\title{
The Supervisory Relationship as an Arena for Ethical Problem Solving
}

\author{
Erika Löfström and Kirsi Pyhältö \\ Centre for Research and Development in Higher Education, University of Helsinki, 00014 Helsinki, Finland \\ Correspondence should be addressed to Erika Löfström, erika.lofstrom@helsinki.fi
}

Received 22 February 2012; Accepted 5 June 2012

Academic Editor: Elizabeth Campbell

Copyright ( $) 2012$ E. Löfström and K. Pyhältö. This is an open access article distributed under the Creative Commons Attribution License, which permits unrestricted use, distribution, and reproduction in any medium, provided the original work is properly cited.

\begin{abstract}
Doctoral supervision involves the analysis of situations and decision making, some of which include ethical perspectives. This research endeavoured to gain a better understanding of the nature of the ethical problems encountered by supervisors. We have interviewed fourteen supervisors in two disciplines: the natural sciences and the behavioural sciences. We have identified the ethical issues in light of five ethical principles, namely respect for autonomy, non maleficence, beneficence, justice, and fidelity. We have located the ethical issues within the supervisory activity in two locations: the dyadic supervisor-student relationship and the academic community. The study shows that supervisors encounter a plethora of ethical issues. Many of the supervisors were highly aware of the ethical challenges in supervision and actively worked to anticipate and prevent ethical problems. The supervisors described a number of sustainable solutions, but at the same time, ethical problems and malpractice were reported. This suggests that the complexities of ethics are not always evident to the actors themselves. We claim that in order to expose and scrutinize supervision practices, it is insufficient to analyse the ethical issues only on dyadic level. What appears to boil down to a dyadic relationship may in fact be indicative of the values, attitudes, norms, and practices of the community.
\end{abstract}

\section{Introduction}

Previous research on doctoral education has identified supervision as one of the central determinants of doctoral experience (e.g., [1]). Ives and Rowley [2], for instance, found that a constructive supervisory relationship was associated with students' progress and satisfaction with their doctoral studies. In turn, problems in supervisory relationships such as lack of supervision or destructive friction have been reported to be a cause of problems in doctoral studies [3] in press. The supervisory relationship provides a context, not only for developing students' academic expertise, but also for ethical problem-solving embedded in the supervision activities. Supervision does not, however, exist in a vacuum between the student and the supervisor but is rather rooted within the various contexts of a scholarly community (e.g., $[4,5])$. The ethical problem-solving embedded in a variety of supervisory activities is the focus of this article. Little is known about the ethical problems doctoral supervisors encounter in their work and how they identify and solve these problems. This paper focuses on exploring ethical problemsolving from the doctoral supervisors' perspective in two disciplines, natural and behavioural sciences.

\section{Ethical Principles in Doctoral Supervision}

A set of ethical principles can be used to identify ethical issues in supervision. In the following sections, we present perspectives on ethical principles and behaviours in supervision, discuss the role of the scholarly community, and describe the characteristics of doctoral training in Finland in order for the reader to gain a sense of the context in which the study was conducted.

Doctoral supervision provides a potential arena for identifying and solving problems in an ethically sustainable manner. However, not all the challenges faced are ethical in nature. Furthermore, the problems are not always solved in ethically sustainable ways. Therefore, well-grounded criteria for identifying ethical problems in the context of doctoral 
supervision are needed. Ethical principles can be used as tools for analysing what can be perceived as problematic from an ethical or moral point of view in a situation such as doctoral supervision.

Kitchener [6], for instance, has proposed the following principles to facilitate ethical decision making in counselling and advising in a university context: (1) respect for autonomy, (2) doing no harm (non maleficence), (3) benefiting others (beneficence), (4) being just (justice), and (5) being faithful (fidelity). Respect for autonomy forms the basis of many ethical codes of conduct, including guidelines for professionals and researchers (cf. [7-9]). The principle postulates an individual's right to decide how to live his or her life, and make decisions concerning one's life. Research on doctoral education has shown, however, that both lack of autonomy (e.g., $[4,10])$, as well as too much independence or even isolation can cause serious problems in doctoral studies. Stubb et al. [11], for example, found that the experience of being isolated and the lack of supervisory support [12] were related to considerations of withdrawal from doctoral studies, as well as lower levels of satisfaction with their studies among doctoral candidates.

The principle of non maleficence refers to the necessary avoidance of activities that would harm others, either psychologically, physically, or socially. There is evidence that doctoral students experience significant degrees of distress during their studies [13-16]. Moreover, the drop-out rates among doctoral candidates range from thirty to fifty per cent, depending on the discipline and the country [1719]. Similar findings have been reported in Finland. For example, Stubb et al. [11] found in their study that 43 per cent of doctoral students had considered abandoning their studies. Several complementary reasons for dropping out and experiencing lack of wellbeing have been identified, including high workloads, frequent evaluations, the competitive atmosphere, the lack of supervision and scholarly community, problems in the supervisory relationship, lack of resources, and problems in combining research and private life $[13,20-22]$. Although the negative experiences and the lack of wellbeing reported by doctoral candidates arise for various reasons, the findings indicate that there is a need to develop more ethically sustainable problem-solving strategies to deal with the problems that doctoral students face.

While avoiding harm, ethical conduct also includes promoting the wellbeing of others, that is, the principle of beneficence. Wellbeing can be promoted in many waysthrough directly helping others, being kind, having mercy, or engaging in charitable acts. Sometimes the situation may require a careful balancing act for the benefits to outweigh the harm when both are potential outcomes of a situation or a decision. Through fairness and impartiality and by promoting equality and reciprocity, one can implement the principle of justice in practice. However, what is perceived as equitable may vary, not only between doctoral candidates and supervisors, but also according to the context.

The principle of fidelity often pertains to human relationships and involves loyalty, truthfulness, keeping promises, and showing respect. Fidelity is often present through an implicit agreement between professionals and their clients [6], or in our case, the supervisor/s and the student. If fidelity in a supervisory relationship is based only on an implicit agreement, then there is the danger that the doctoral student's and the supervisor's expectations and beliefs about the working practices are not aligned, which may in turn cause conflict. We find it necessary to expand the principle of fidelity to include the scholarly community in which the supervisory relationships take place. The community, the supervisors, and the doctoral students are members of a complex interactive system in which norms, values, and shared practices are constantly constructed and renegotiated; hence, students and supervisors can keep, reconstruct, or break promises to each other. Moreover, students may engage in or attempt unethical conduct, which can challenge the supervisor's skills in ethically sustainable decision making. A community with a pronounced ethical value basis and a strong sense of ethics supports its individuals, including supervisors, team members, and students, to act in accordance with those values.

\section{Ethical Practice in Doctoral Supervision}

Ethical practice can be seen as the manifestation of ethical principles. This means that criteria for ethically sustainable problem solving can be reflected in principles of ethical practice. Applying Welfel's [23] criteria for the ethical behaviour of counselors in the context of supervision, we point to the following criteria: (a) the supervisor possesses skills and knowledge to facilitate the process, for instance, through various interventions; (b) the supervisor respects the human dignity and autonomy of the student; (c) the supervisor uses the power inherent in his or her position responsibly; (d) the supervisor acts to promote public confidence in the way research communities function. In the context of academic supervision, these criteria imply the necessity of a sufficient knowledge base in the field in which the research is conducted together with methodological competence and an understanding of research ethics. There is evidence that doctoral students rarely [12] and supervisors to a limited extent [24] perceive the lack of domain-specific expertise as a core problem in the supervision. One reason may be that supervisors are usually experts in their field and hence are able to provide sufficient guidance and advice to students in conducting thesis research. Doctoral studies are not, however, only about learning research skills and acquiring knowledge; they are also about becoming a full member of a scholarly community and developing an identity as a scholar [25]. To facilitate the doctoral process successfully, an understanding of human learning, that is, pedagogical knowledge, is needed.

The second criterion essentially boils down to the first of Kitchener's [6] ethical principles, that is, allowing the doctoral candidate to make fundamental decisions regarding his or her life. In practice this could mean recognizing when a candidate simply is unable, for any reason, to pursue doctoral studies further, and allowing the candidate to make the decision that he or she finds the most satisfactory. In 
the context of supervision, respecting human dignity can be understood as allowing the novice researcher to engage in a learning process without fear of being humiliated because of lesser knowledge and experience in the field. Acknowledging the asymmetrical power relationship in supervision will allow the supervisor to use the power inherent in his or her position wisely. However, supervision and ethical problemsolving in the context of doctoral education is not limited to a dialogue between the doctoral candidate and the supervisor, but it is influenced by practices of the scholarly community.

\section{The Scholarly Community in Supervision}

Supervision is often embedded in the practices of cosupervision, the activities of a research group or seminar group or the practices in the disciplines. Accordingly, during the doctoral process, students are exposed to various pedagogical subcultures; they participate in different kinds of peer groups and adopt various roles in dynamic and complex communities of practice (cf. [26, 27]). Ethical problem-solving often takes place in multilayered and dynamic communities rather than in supervisor-student dyads $[28,29]$. Students engage in cognitive apprenticeships [30] in carrying out their doctoral thesis [19].

However, the signature pedagogy of doctoral training has been the implicit apprenticeship, either in a studentsupervisor dyad or in a research group [4]. These practices have their own cultural roots and reflect the values, norms and conceptions of a certain research domain while also being multi- or interdisciplinary in nature [31]. The attitudes and behaviours of faculty members effectively convey the true ethical standards in the community $[32,33]$.

Unspoken rules and practices exist in various scholarly communities and that doctoral candidates generally learn them without explicit guidance. The role of the academic community is clear in the research by Anderson et al. [34], who found that the students who had the best opportunities to learn research skills, that is, who collaborated closely with faculty in research projects, were also the most frequently exposed to unethical behaviour. The researchers suggest that greater focus should be placed on research communities and their role in fostering future generations of academics. The multilevel and sometimes contradictory practices provide opportunities for agency, avoidance, opposition, and resistance. Consequently, tension inevitably arises in interactions between different actors in these contexts [35, 36]. When faced with such practices, doctoral students can use a variety of strategies: they can adapt to, ignore, or adopt the practices, or they can leave the community [37]. At its best, this dynamic and complex interplay involves participating in various complementary practices that contribute to the gradual acquisition of expertise in one's own domain. However, sometimes the community of practice fails to provide doctoral students with adequate support and shared control. This may lead to continuous destructive friction between students and the learning environment, which can be reflected on the community level as ethical problems of supervision.

\section{Doctoral Education in the Natural Sciences and Behavioural Sciences}

In Finland, a significant portion of doctoral education takes place in conducting the research for the thesis. The doctoral degree includes the doctoral thesis, seminars, course work, and a public defense of the thesis. The research project is launched at the very beginning of the doctoral studies. The course work (between 40 to 80 ECTS (European Credit Transfer System in which 1 credit equals 27 hours of study.) credits, depending on the discipline) included in the studies is usually individually constructed and based on personal study plans that frequently include international conferences and methodological studies. The emphasis in doctoral programmes is on conducting research. There is no separate extensive course work before launching the doctoral research; instead seminars and course work are complementary to the thesis project and designed to support it. Students need to apply for doctoral education. However, once permission is granted for the doctoral studies, it has, until very recently, been valid for life. Accordingly, it can be argued that characteristic for Finnish doctoral education is that it is quite unstructured [38] compared to many other European countries and highly embedded in conducting doctoral research, although more systematic pedagogical models have been developed during last decade.

The doctoral thesis can be done either in the form of a monograph or as a series of articles including a summary (Finland's Council of State's regulation of university degrees $645 / 1997)$. In the natural sciences the majority $(81 \%)$ of doctoral candidates pursue article-based dissertations [1], which consist of three to five internationally refereed journal articles coauthored with the supervisor and other senior researchers, and a summary that includes an introduction and a discussion bringing together the separate articles. Accordingly, doctoral candidates in the natural sciences often work intensively in relatively strong research communities that consist of several doctoral students, post docs, and professors who focus on collectively solving shared research problems related to the supervisor's research projects. In most cases, the students' mother tongue is Finnish or Swedish, but the articles and the summary are often written in English. Also in the behavioural sciences the article compilation with a summary has become the dominant form $(66 \%)$ of theses in recent years [1]. However, there is more variation among the domains within behavioral sciences in terms of the primary form of the doctoral dissertation. For instance, the article compilation is more dominant in psychology, while monographs are more often carried out in the field of educational science. The doctoral students who pursue monographs often engage in seminars, and supervision is based on supervisor-student dyads rather than intensive work in research groups. Doctoral supervision is, however, usually based on an apprenticeship, both in the research groups and in the supervisor-student dyads.

The average time for completing the degree is five to six years [39]. The doctoral education is publicly funded and does not cost the student, but they have to come up with their cost of living expenses. Students do not automatically 
get funding for conducting their studies by launching their doctoral project. The most used funding form among doctoral candidates is a personal grant, project funding, or wages earned by working outside the University [1]. Hence, during their studies doctoral students usually apply and gain funding from various different sources. This is also reflected in their roles in the academia. Doctoral students typically adopt various roles during their studies ranging from junior staff member, such as research assistant, teacher, or project researcher to student. This means that the relationship can include a wide range of supervisor roles, for example supervision of the student's doctoral work, supervision of student's work in the supervisor's project, and collaboration with the student on a consulting project for private industry. At its best the various roles can be complementary and promote doctoral student development as a scholar, but sometimes destructive frictions and role conflicts may occur.

Each student has at least one advisor (a full professor in the field in which the thesis is being done) and one supervisor. Also the use of supervisory boards has become more popular in recent years [15]. The evaluation process of the doctoral thesis consists of four stages. After the manuscript is accepted by the advisor and the supervisor(s), the Faculty Council will name the prereviewers (usually full professors from other national or international universities) to examine the thesis. The manuscript is read by the prereviewers, and the doctoral candidate revises it based on their comments. The Faculty Council then decides whether the student will be given permission to defend the thesis publicly and names the opponent. At this stage, the thesis is printed, published with an ISBN number and sent to the opponent. After the doctoral candidate has publicly defended the thesis, the opponent decides whether he/she will recommend its ratification. Finally, the Faculty Council decides whether to award the doctoral degree.

\section{Research Task and Method}

6.1. Aims of the Study. This study endeavours to gain a better understanding of the nature of the ethical problems encountered by supervisors of doctoral candidates. Moreover, we focus on exploring the various strategies used to solve the problems. The research questions addressed in this study are as follows: What kinds of ethical problems do supervisors in the natural sciences and behavioural sciences encounter in their work? In what kinds of practices are the ethical problems situated? How do the supervisors solve these problems?

6.2. Participants. The present investigation analyses interviews of 14 supervisors in two domains-one in the natural sciences and one in the behavioural sciences in a major Finnish research-intensive university. Eight supervisors from the natural sciences and six supervisors from the behavioural sciences were interviewed (three female, eleven male). All participants had $\mathrm{PhD}$ degrees and most also had several doctoral students under their supervision. The participants included in this study are members of active research communities.

Many of the investigations in the natural sciences involve methods and practices of collecting data in field settings, whereas in the behavioural sciences the research is more often conducted by a single researcher. Both research communities collaborate with several research communities worldwide.

6.3. Method and Data Collection. The present investigation is part of a larger national research project on Finnish doctoral education [28]. The supervisor interviews were conducted in the research communities during the year 2007. The data were collected with semistructured thematic interviews, and it included questions on three wider themes: (1) the doctoral process, (2) supervision practices, and (3) oneself as a supervisor. The interview instrument was intended to obtain a wide view of the supervisors' work and especially of the different aspects of supervising doctoral students. All questions and instructions were validated by the members of the research group before the interviews. Altogether, the interview contained eighteen questions on different aspects of the supervisors' work and six background questions on the participants' working history, years of supervising, and current position. None of the questions explicitly addressed ethical challenges. Experiences in facing ethical problems emerged in the interviewees' reflections on their work as supervisors. Our focus is on the kind of ethical issues that emerge in supervision, not how the supervisor's identify and conceptualise ethical challenges in supervision. Hence, to reach our aim of capturing authentic manifestations of ethical problems embedded in supervision, the ethical issues needed to be studied as such. Had we explicitly asked about ethical issues in supervision, we would have ended up with the supervisors' conceptualisations, which may have differed from the ethical issues that we have now identified.

The data were collected by one of the authors of this paper during fieldwork in the research communities. Each interview took between 60 and 90 minutes to complete. The interviews were tape-recorded digitally and transcribed into text files by two trained research assistants. All supervisors participated voluntarily. Owing to the sensitive nature of some of the data, we have not provided background information in connection with the interview quotations. We have also neutralized any references to the gender of the interviewees or the people they have referred to.

6.4. Analysis. We explore the episodes that challenged the supervisors' everyday practices. Through the episodes, the supervisors' experiences of encountering and solving ethical problems can be located in specific contexts and events in the supervisory processes. The data were analysed by content analysis. The analysis strategy involved both deductive and inductive processes. The first step was deductive in the sense that we used Kitchener's [6] five ethical principles as a framework for recognising ethical issues in the data. Based on this analysis, we extracted phrases from the interviews so that the unit of analysis was a whole thought or theme. 
TABLE 1: Ethical principles, related issues, and frequency in the data.

\begin{tabular}{llcc}
\hline Principle at stake & Ethical issues & Frequency $(f)$ & Percentage of ethical issues $(\%)$ \\
\hline \multirow{2}{*}{ Avoiding harm } & Exploitation and abuse & 19 & 36 \\
& Dual relationships & 10 & 17 \\
Beneficence & Competence and adequacy of support & 4 & 8 \\
Autonomy & Boundaries of supervisor role/support & 8 & 13 \\
Fidelity & Conflicting demands & 5 & 9 \\
Justice & Abandonment & 7 & 13 \\
\hline & Inequity & 2 & 4 \\
\hline
\end{tabular}

At this point we ended up with a total of 63 units, which through an iterative process were reduced to 55 retained units. After the initial identification of ethical issues, the analysis took an inductive turn, as we categorised the ethical issues under seven data-driven categories based on the nature of the issue (e.g., exploitation, lack of autonomy). In line with a content-analytical procedure (cf. $[40,41]$ ), we made abbreviated descriptions of each unit of analysis.

The next phase was to locate the ethical issues within the supervisory activity in which it appeared. We distinguished between two locations: (1) the dyadic supervisor-student relationship and (2) the academic community (e.g., the research group, department, faculty). In the third phase we identified the ways in which the ethical issues were or could be solved. The analysis was conducted by the first author, but the interpretations were tested with a dialogic reliability check [42] to guarantee agreement between the researchers.

\section{Findings: The Complexity and Multidimensionality of Ethical Issues in Supervision}

The supervisors described a variety of events which they considered ethically problematic or challenging $(f=55)$, ranging from short events to extensive series of episodes. For example, they described exploitation, destructive friction in supervisory relationships and dual relationships. Moreover, there was variation among the supervisors' experiences. Further investigation showed that the source of the problematic episodes varied. The results suggested that a range of ethical issues potentially breaching the five ethical principles (cf. [6]) were present in the supervisors' experiences and in their conceptions of supervision. The issues were categorised by the ethical principles that might be breached according to the scheme in Table 1.

More than half of the ethical issues pertained to exploitation, abuse or dual relationships. Role ambiguity and conflicting relations and supervision abandonment accounted for approximately a fourth of the ethical issues as reflected by the supervisors. Fewer in frequency were the issues that pertained to supervision competence and adequacy, conflicting demands in supervision and inequity. The theme of dual relationships emerged with equal frequency among the supervisors in the natural sciences as in the behavioural sciences $(f=5 / 5)$; however, the theme of exploitation and abuse emerged more frequently within the natural science domain ( $f=13 / 6)$, which is not to be interpreted as natural sciences harbouring more frequent cases of exploitation and abuse. It merely demonstrates the multidimensionality of the ethical issues that can involve exploitation or abuse. Issues ascribed to the supervisor's lack of competence ( $f=0 / 4$ ) or inequity issues $(f=0 / 2)$ were not mentioned by the behavioural science supervisors, whereas these issues did emerge among the natural science supervisors. In contrast, pressures arising from conflicting demands were more frequent among behavioural science supervisors $(f=1 / 4)$.

\subsection{Principle: Avoiding Harm}

7.1.1. Exploitation and Abuse. Exploitation was a theme brought up frequently by the supervisors. But rather than being a relatively straightforward phenomenon, with one person being the exploiter and the other, the exploited, it proved to be a much more complex area of ethical problems. One of the forms of exploitation had to do with differing views as to what is acceptable supervision. For instance, supervisors hesitated over how much of their own contribution to an article is acceptable and when the contribution might be viewed as exploiting a student's work, even a form of "free riding". Another viewpoint was that the article dissertations are the work of the supervisor, not the student, and would thus not represent the student's actual contribution. A solution suggested by one supervisor was the unification of practices with the introduction of a detailed description of the student's own contribution to the articles included in doctoral dissertations. This suggestion works well to alleviate suspicion of both contribution of the student and the supervisor:

\section{When I first got here I heard comments that they [the article-based dissertations] are written by the supervisors, and I suggested that we adopt a practice similar to that in the medical school where the students write a report for each article, describing their own contribution.}

Supervisors felt the need to protect their supervisees against exploitation or abuse by fellow colleagues. One supervisor described a situation in which a colleague was considered to be taking advantage of the doctoral student's research work. In this case, the colleague was said to have 
belittled the student's input and tried to exclude the student from article authorship. The supervisor had found direct confrontation to be the solution, taking the side of the student against the colleague. Again, clear rules on what counts towards authorship accompanied by a contribution report might have helped the parties settle the conflict.

In one case, the supervisor's own superior was seen to be exploiting the doctoral students, requiring them to do tasks that neither related to nor advanced their studies. In order to secure their income, students may need to work, a situation that sometimes results in over-work or in other projects that do not directly advance the doctoral studies. While a supervisor argued that it is important for the students to carry out a variety of academic tasks during their doctoral studies, one supervisor had solved similar incidents with colleagues by appealing to them not to ask the students to work for them, as the students would find it hard to decline a request from superiors:

\section{Sometimes I've had to say, had to forbid people to take on work chores unless they come from me; forbid all other supervisors to give certain persons any tasks. No one is allowed to ask [the students] for anything anymore.}

One supervisor described a situation in which the student had to be protected from another type of abuse, namely racist attitudes and behaviour. The supervisor had arranged a workplace for a gifted graduating international student. The supervisor then heard of racist attitudes towards the graduate in the workplace and felt responsible for the situation:

\section{Of course, I was thinking that he [the student] would need to find employment after finishing the doctoral studies, and then drifted into an unpleasant situation that I hope wasn't too evi- dent to the student: There was racism in the work place. Considering the situation, I was quite satisfied that I had used my energy to promote the student's wellbeing without thinking so much about the project, that the project was of secondary importance, and first I needed to organise the student's personal environment in a way that the student could be in a good environment.}

Students may not be the only objects of exploitation or abuse. The data included four descriptions of a supervisor experiencing exploitation. Supervisors felt exploited when their supervisees made claims beyond the legitimate sphere of the supervisory relationship. Such claims could be related to demands for assuring employment after graduation, or a student could endeavour to turn the relationship into a therapeutic one. In the following excerpt, the supervisor was very clear about where the responsibilities of the supervisory relationship end, yet encountered situations in which this understanding was neither shared by the student nor the community:

It's after all their life. You can follow it with interest and be supportive, but if you start to be too proud of them and live off them, giving them job offers they wouldn't otherwise receive, it's getting dangerous... I know that there are supervisors who do a lot more, and I shun it very much. But, of course, some students also expect their mentor and supervisor to be a recruitment office. And that's when I say, hell, no! It's not our job to fix jobs for people. Or matchmaking or anything like that. That's that other part of life.

Whereas above the exploitation is viewed as taking place between individuals, a category emerged, in which a system, that is, the university or a department or even policies, could be exploitive. Some supervisors found it problematic that doctoral students are recruited in order to maximise the government funding of the department, as funding depends to a certain extent on the number of graduating $\mathrm{PhDs}$. The ethical problem is that students are often recruited to uncertain careers, and five of the supervisors interviewed expressed concern over the career prospects of the graduating students. The supervisors felt that sometimes students are recruited merely to secure maximal departmental funding rather to foster a new generation of scholars:

With regards to doctoral dissertations, I wonder
how much we really should encourage people to do
dissertations when the situation in the universities
is crazy, and this is a tough place for doctoral
students and PhDs who don't get employed and
don't get a decent salary. Really, really, I think
about my own morals and whether it is right to
recruit these most talented young people to do
PhDs.

7.1.2. Dual Relationships. Dual relationships as ethical issues in the supervisory relationship were identified by four supervisors. We have categorised dual relationships as a category of its own, although in some respects these may be just another form of exploitation. The reason for keeping dual relationships as its own category is that these were emotionally or psychologically confounded relations. The supervisors described it as a problem or challenge when the relationship between the supervisor and supervisee took other forms, such as a deep or intimate friendship, or started to serve psychological needs, that is, parent or therapist, normally associated with relationships other than a supervisory one:

Close friendships and best friends develop into
romance surprisingly seldom considering that all
are adults. This hasn't been the biggest problem.
But the emotional involvement, friends and family
friends... It easily turns into father-son, father-
daughter, mother-son, mother-daughter relations.

The supervisors had different suggestions for dealing with such emotional complications. One suggested that assigning same-sex supervision dyads would reduce the tensions that arise in mixed-gender relationships. Another supervisor permitted infatuations and also allowed colleagues to speak of their supervisees using what could be 
described as derogatory language. The supervisor claimed that by admitting the infatuations, it was possible to control the situation and one's behaviour:

I know that I am regularly infatuated with [the student], but that's all right, because I have admitted it to myself a long time ago. I don't try to struggle with it, because then in a postdissertation party when dancing slow dances, it'll blow up in your face. But because I admit, OK, I'm infatuated with [the student] again this week, nice, it stays in control precisely because I communicate with the thought, and I don't try to say "I'm not, I'm not and that thing doesn't exist", because that way it won't work. I don't know how these things should be dealt with in the work community, and it would be good to have some agreement, because we clearly have cases here. For instance, one supervisor said to me that $X$ is a bit slow, but nice to supervise because the student is physically attractive. And because I know this person well, and I'm myself what I am, I don't feel bad about this at all. I just think it's OK that it's been voiced.

Speaking derogatorily about someone, particularly a person in a weaker power position, places that person in an even more disadvantaged position and can further enhance the power differential. Accepting sexually-loaded ways of speaking about students may signal that dual relationships are, if not common practice, at least an accepted norm in the research community.

One supervisor described the experience of being caught up as a student in a supervisory relationship that can only be characterised as abusive:

That supervisor was an ass. And still is. In other words, a socially disabled person, who apparently suffers from unfathomable shyness or other problems, which takes the form of being an asshole; an evil, sharp-tongued person who tells you that "you have no brains". Well, then I drifted into an intimate relationship, mostly because the only way to communicate with the supervisor was to go to the bar with [the supervisor] because when [the supervisor] was drunk one could get supervision. Really! And then, of course, I got addicted to the attention, because it was so difficult to get.

The coarse language, which contradicts much of the tone in the rest of the interview, suggests that there is an unresolved emotional burden attached to the incident. The problem appears to have escalated by the private nature of the supervisory relationship. One may ask how it is possible for such a situation to have persisted without anyone in that community reacting to what was going on. It appears that the community has been unable, perhaps even unwilling, to undertake any measures against exploitation and abuse when the supervisory relationship has been viewed as a private matter. Reducing the supervision to a private relationship deters the community from taking responsibility and taking action to implement more candid supervision practices, even when there is a justifiable case for intervening.

One of the supervisors referred to the necessity of maintaining a professional stance in the supervisory role in order to support the students in times of need. The supervisor was guided by an understanding of the nature of the doctoral process and the mandate of the supervisor, which included a clear definition of one's own role:

I have made the decision that I can be very close and they can talk to me, but I am their supervisor. I am not their friend. That doesn't mean that I can't be close to them or democratic, but it means that in times of crisis during the dissertation process, be it self-doubt or doubt about mastering the whole thing or a rejection from a journalthere are many such things-and if I am their nice friend, I cannot be the supporter of the process when a crisis arise... I try to keep the roles clear. Otherwise I cannot help them when they despair.

\subsection{Principle: Beneficence}

7.2.1. Competence and Adequacy of Support. Adequacy and supervisor competence were themes that appeared to trouble the natural sciences supervisors in particular. Four of them discussed competence and adequacy through themes such as doubting the worth of one's own contribution, experiences of insufficiency, inexperience and lack of pedagogical training. The supervisors have a mission to do their task well, but attributed shortcomings to their own performance, which, in their minds, compromise the principle of benefiting the students. These experiences result in bad conscience and guilt:

I sometimes have the feeling, a bad conscience, that I have nothing to contribute to this student, because [the student's] brains produce such things that go beyond my comprehension.

Not all problems were attributed to shortcomings in knowledge. The supervisors acknowledged that their lack of understanding of the learning processes created or at some point in their career had created problems. The following dialogue describes the supervisor's experience of such a situation and reflects that knowledge about support structures may not have reached all parties who could have benefited from the support:

Supervisor: Are we training supervisors here now in any way to supervise doctoral studies?

Researcher: Well, do you?

Supervisor: No [laughing]. Not really for supervision, there is no training here, which could be a way to develop doctoral studies.

In addition to preparing academics to supervise the doctoral students' research processes, supervision training 
can help community members clarify their vision of good supervision practices. This will allow the community to share the responsibility of developing such practices, instead of leaving individual supervisors to sort them out for themselves. The shared vision and responsibility allows the individual supervisor to judge his or her own competences and the adequacy of the supervision in more objective terms and allows the supervisors to seek consultation when their competence is insufficient.

7.2.2. Boundaries of the Supervisor Role and Support. Ambiguity in what constitutes the supervisory role could cause problems in terms of the benefits gained from the relationship. The following quotation shows that even experienced supervisors grapple with the nature of the task:

It is a relationship that's in a way very intensive, but you work together, so is it comparable to the arts; theatre or film-making, like the kind of relationship that exists between a director and an actor?

Looking for guidance for the supervisory role from the director-actor relationship may be misguided in that both a director and an actor are professionals in their own right, whereas the doctoral student generally is a novice in academia and needs guidance to develop into an independent researcher. The power constellation inevitably places the supervisor and the doctoral student at different ends of the continuum. As the doctoral process evolves, the power constellation may shift towards greater equality, but if this is taken as the point of departure, we see that there are great risks for missing the core of the supervision task and for misuse of power.

Another issue involved collegial relationships in the immediate community, which prevented the student from gaining optimal support from the supervisors. The supervisor role itself was not the arena of ambiguities; rather the strained relations with coworkers affected the progress of the doctoral studies:

The leader of this research team is in considerable conflict with another person... and now there is a new twist: these two persons cannot have their name in the same publication, which sounds strange, but there are many background variables. I work with both people, cooperate quite successfully. And now the problem is that I can't use the strengths of these two people, can't have them both in my doctoral student's work. It has caused problems in the past, and still does.

Inflamed interpersonal relationships that hinder people from cooperating are a serious threat to any team or community, and there are likely others who suffer in these situations in addition to the doctoral students.

A third form of role-related issues extending beyond the supervisee-supervisor relationship included the ambiguity of the supervisor's role in relation to the research community. The community may embrace practices that benefit the doctoral student, but simultaneously other practices may work against the student. The following excerpt illustrates this point through the different demands placed on supervisors by academic and financial policies:

University departments compete with each other, but the national doctoral school tries to support mutual doctoral candidates. We spend a lot of time, top researchers spend a lot of time, supporting the doctoral students of supervisors in another university, and the department doesn't view this favourably.

Defining the responsibilities not only of supervisors and doctoral students, but also of the community (team, department, university), and making these explicit to everyone would alleviate the issues that arise from supervisor role confusion and unclear boundaries of the supportive task.

\subsection{Principle: Autonomy}

7.3.1. Conflicting Demands. The supervisors described a number of situations in which they had experienced the ambiguity between supervision and imposing on a student's autonomy. For instance, they recognised that forcing a viewpoint or simply adhering to contextual pressures might interfere with the student's learning process. In the quotation below, the supervisor recognises a conflict between supporting the students in dealing with the system and allowing the students to engage in a developmental process:

Especially now that there are a lot of projects and tight deadlines and so on, in order to alleviate the pain of creating something new, they [supervisors] give ready reading lists, for instance. And that is a big service, but it can also be quite a big disservice. It's this old issue that if you give bread to the hungry, you can ease his hunger today, but teach him to farm and he won't be hungry for the rest of his life... There are the EU grants. But the system is wrong. The world today is tuned so that it takes away some extremely valuable states of mind, which we should learn to recognise and tune up and allow people the spaces and the time to stay there, and that way support them.

Another type of ethical dilemma emerged in situations in which the supervisor's and supervisee's views differed. Insisting on the viewpoint that the supervisor knew to be right would, in the long run, have made things easier for the student, but that would not have been the student's own decision, which is one of the valuable aspects that students should learn during the doctoral process. Ethical dilemmas of a similar nature also appeared when supervisors felt unsure about how persuasively to insist on their own view rather than give in to the student's perhaps unconventional ideas:

The doctoral student receives, but simultaneously also preserves or develops his or her own perspectives, which at best deviate in interesting ways 
from the supervisor's ideas. So it is difficult because you never know when you might have pushed an idea too strongly and prevented the doctoral student from developing his or her own idea, or the other way around: when you should have been more forceful and not left it up to the student to decide.

Furthermore, an issue involving student autonomy is the acceptance by the supervisor that the supervisees will exceed the supervisor's grasp of knowledge and eventually go beyond what is currently known in the field. Supporting the supervisee's development is a theme that came up in most interviews, and as such it may not pose a dilemma. It may, however, become an ethical issue if the supervisor or the community does not accept that the student may accomplish greater things than the supervisor or the state-of-the-art in the community. In most interviews, supporting the student in this process was described as a satisfying task, and seeing the students excel was described as one of the greatest joys of supervision. One of the supervisors also described feelings of jealousy and the necessity of mastering those feelings in order not to impose on the student's right to build a successful career.

\subsection{Principle: Fidelity}

7.4.1. Abandonment. Of the examples of supervision abandonment in the interviews, all but one pertained to the supervisors' own experiences of being supervisees. Abandonment took the form of indirect abandonment, lack of support, inadequate supervision, or inappropriate interference. One supervisor described delegating the supervision of a student to a coworker incapable of providing adequate supervision, which resulted in involuntary abandonment of the supervisee. There appears to have been the potential of utilising the research team as a supervision resource, yet the supervision relationship only shifted from one dyadic relationship to another, that is, it remained highly private in nature, which prevented the team leader or others from interfering with the neglect.

Other experiences included the lack of support from a supervisor owing to different research approaches and inappropriate interference from the supervisor. In one case the interviewee had tried to avoid the supervisor, who mostly interfered in a nonsupportive way. Similarly, in another case, the supervisor recalled his/her own doctoral studies and the supervisor's flagrant feedback. Such experiences had led the supervisors to reflect on the importance of a respectful attitude towards the student, even if there is disagreement on the subject matter itself. Further, one of the supervisors had gradually stopped taking new supervisees and started to extend and gradually transfer supervision responsibility to graduates so that at retirement there would be a smooth transition and no doctoral student would have to feel abandoned.

\subsection{Principle: Justice}

7.5.1. Inequity. Supervisors realised that there is the expectation of equal treatment among students, but at times the understanding of what equal treatment entails was contradictory. From the supervisor's perspective, equality may not necessarily mean similar tasks and an equal amount of work, which, according to one of the supervisors, is what students expect. Balancing the tasks in a way that is experienced as fair to all is difficult. Part of the problem may also be the expectations that the supervisors have for themselves. They may embrace the ideal of fair and just supervision, but realise that in practice it may not mean treating all supervisees in the same way:

What the doctoral students want from the supervisor is some kind of fair treatment. And it is a bit tricky because you might yourself think that you are treating them all in an equal way, but that doesn't automatically mean that you give them all the same jobs and the same amount of work. From my perspective, I see that to some students I can give certain tasks and that much more work, and so on. In my opinion, it should be related to their skills and capacity, and that is fairness, but they don't see it that way. They want everything to be exactly the same... That's a problem because you should treat them in a fair way, but true equality where everything is shared just the same is impossible.

Supervisors may also fear accusations of favouritism or exploitation, which makes the quest for equality all the more urgent. Candidness in the responsibilities of individuals in the community as well as open communication about various opportunities that arise favour a just work community.

Another issue that potentially breaches the ethics of justice was identified by one of the supervisors, who was concerned that students are held responsible for things that they may not always be able to influence. Naturally, the doctoral dissertation is an inquiry in which the student demonstrates the ability to carry out research. Sometimes the direction that the project takes is influenced by the grants that a research team acquires, and it may not be fully up to individual students to make all the choices themselves. If the student nevertheless is held responsible, this may create a sense of unfairness:

It is, of course, a bit unfair that the doctoral student can't always be responsible for what's been investigated because in a way it is determined by external sanctions, for instance by what is funded.

Group support plays an important role in the direction that the individual student's research may take, especially in communities where research is usually conducted in teams. Part of the support entails responsibility for the group as a whole and for the individual researcher within it. 


\section{Discussion of Ethical Problems in Supervision}

Our study shows that supervisors encounter a plethora of ethical issues in supervision, and they are sensitive to the ethical nature of the problems. The supervisors interviewed for this study sought ways to solve the ethical dilemmas, and many actively worked to anticipate and prevent issues from turning into problems. The supervisors described a number of ethically sustainable solutions to the issues and problems they encountered. At the same time, serious cases of malpractice were reported, suggesting that the complexities of ethics and sustainable solutions are not always evident to the actors in the supervision arena.

Prior research identifies a variety of ethical issues in supervision, including incompetent and inadequate supervision, supervision abandonment, intrusion of supervisor values, abusive and exploitative supervision, dual relationships, encouragement to commit fraud, and authorship issues [43]. We identified many of these in our data, with the exception of fraud. Asking people to be honest about their dishonesty is methodologically problematic (e.g., [44]) and may require other approaches than a thematic interview. Nevertheless, the interviewees did not describe any fraudulent behaviour of colleagues or students either.

Abusive and exploitative supervision relationships were the most frequent type of ethical issue. Although conceptually close, exploitation and abuse may arise from different kinds of motivation. Exploitation generally serves a selfish end such as using a student to advance one's own goals, even if this may prevent the student from finishing the dissertation. Abusive supervision springs from a motivation to punish the students, for instance, for their lack of skills and experience in the field (cf. [43]). Exploitation or abuse may work in two directions. Our data show that the exploiter as well as the object of exploitation may be the supervisor, the student or the community, or even the system. Our data indicated an additional twist on the theme, namely, supervisors who experienced the need to protect their supervisees from exploitation by others.

Dual relationships emerged in our data as well. In academia, faculty and students interact in various contexts and situations, which, despite a number of similarities, are more variable and sometimes less constrained than the settings in which therapist-patient relationships take place, for instance [45], in [43]. Mutual interests and values may provide a basis for attraction, paving the way for emotional contagion. The asymmetrical power relation increases the vulnerability of the student [4], and generally places the student at greater risk for harm than the faculty member. Reducing the supervisory relationship to a private matter increases the risk that exploitative and abusive relationships will take place without interference by the community. The kind of language in which supervisory relationships are talked about within a community may be indicative of the community's accepted norms. Scrutinizing the discourses can reveal discriminatory and oppressive norms.

Goodyear et al. [43] has identified authorship as an ethical issue in supervision. Our data gave evidence not only of ambiguities related to authorship, but more broadly, to work contributions in general. The supervisors often attempted to solve these ambiguities at the level of the individual relationship, rather than scrutinizing the norms and practices on the community level. If a community is unable to resolve its conflict by itself, then an external mediator may be called in to provide the community members with tools for conflict resolution.

Incompetence with regards to subject matter and methodology can stop benefiting the supervisees or even harm them [43]. Based on our data, incompetence also included the lack of pedagogical knowledge or a perceived incompetence in pedagogy. We also recognised in our data ethical issues that arose from unclear boundaries in the supervisor's role and the extent to which the supervisor should give his or her support. When supervision is primarily viewed as a dyadic relationship, recognising the responsibilities and resources of the community can be difficult. At the other end of the continuum of assuming all responsibility oneself as a supervisor is supervision abandonment. In our data, the references to abandonment were related to the supervisors' own experiences of being doctoral students, and many emphasised that, based on their prior experiences, they knew what kind of supervisor they did not want to be. Even if the neglect might not go as far as abandonment, experiences of exclusion or belonging could have serious consequences: scholarly communities have been suggested as playing an important part in doctoral student wellbeing and students' commitment in their studies [17, 20, 46]. Pyhältö and colleagues [28] for instance, found that seeing oneself as an outsider to the scholarly community was related to a lack of interest in the studies, considerations of dropping out, and experiences of exhaustion, anxiety, and stress.

Our data do not allow us to make inferences about the field-specific nature of ethical issues, and we can only hypothesise about the possible relationships between a discipline and the types of ethical issues. Could the more frequent occurrences of references to exploitation and abuse within the natural sciences be related to the fact that students work in teams with many supervisors overseeing students and with several projects being carried out simultaneously? The boundaries of who is supervising whom and who participates in what projects in which ways may be unclear, and the work distribution arising in such a situation, may be experienced as exploitative. Perhaps the fact that the quest for equity also arose more frequently from the natural science data could be a reaction to experiences of exploitation. Another explanation may be that in many areas in social sciences it is typically the case that students approach the supervisor with whom they would like to work. When applying for doctoral studies, the student thus has the support of a supervisor, who is ready to make a commitment to the supervision, should the student's application be accepted. In the latter case, that is, typically in natural sciences where doctoral studies are conducted within a research group, appointment of supervisors is done by the leader of the research group, and there is less gravitation of students towards working with individuals. In such situations it is vital that commitments and responsibilities of all parties involved are negotiated 
explicitly. When students seek supervision from a chosen individual, the commitment of the two parties is perhaps more explicitly dealt with prior to beginning the supervision. In these cases, however, there appears to be the risk of conflicting demands and related pressures accumulating on one individual.

Lack of supervision competence did not emerge as an ethical issue among the supervisors in behavioural sciences. The field in itself neither guarantees adequate or competent supervision nor does it automatically endorse the supervisor's experience of his or her own competence. Yet we are confident in proposing that pedagogical training in general and supervision training more specifically provide knowledge and skills that are useful in the supervision process of doctoral students.

Our findings suggest that the ethical issues which supervisors encounter are challenging and multidimensional. As such, they also require problem-solving on many levels. It is insufficient to focus only on individuals and their actions. This suggests that supervision of doctoral students is in the interest and the responsibility of the research community, for example, the research team or institution, rather than being the task of individuals. This is not to say that the dyadic relationships are not important; rather it is insufficient to analyse the ethical issues only on that level. What appears to boil down to a dyadic relationship may in fact be indicative of the values, attitudes, norms, and practices of the community. Pedagogical and supervision training are means of working with and solving ethical issues in supervision on the community level. The training provides an arena for sharing good supervision practices and ethically sustainable solutions, which also our data provided evidence of. Training can provide further tools with which supervisors can scrutinize the current practices and discourses in their research communities.

On a final methodological note, we recognise that there are limitations to our research approach. The supervisors were interviewed about their supervisory experiences as a whole, and it is possible that they remembered some incidents differently from what actually occurred owing to the retrospective nature of recall. However, we were striving for understanding perceptions of a certain phenomenon rather than recording the experiences of a particular event; moreover, perceptions can be considered to develop over a longer period of time instead of being allocated to certain situations.

The supervisors were interviewed only once, and it is possible that certain aspects of the interview situation (e.g., mood, the latest incidents in the doctoral supervision) or the current research or the life situation in general may have affected their responses. The primary aim of qualitative research, however, is not to describe individuals' perceptions per se, but to increase the understanding of the variation in perceptions at the collective level [42]. From this perspective it can be considered a strength of this research that the data consisted of supervisory interviews from two communities in two scientific fields. All the supervisors were quite experienced; however, they were in different phases of their careers as academics, and we believe that this in some ways heterogeneous group provided an overall picture of the kinds of ethical problems supervisors may encounter.

\section{Acknowledgments}

The study was supported by the University of Helsinki (Grants nos. 2106008 and 7630108) and by the Academy of Finland (Grant no. 252813).

\section{References}

[1] K. Pyhältö, J. Stubb, and J. Tuomainen, "International Evaluation of Research and Doctoral Education at the University of Helsinki-to the Top and Out to Society. Summary Report on Doctoral Students' and Principal Investigators' Doctoral Training Experiences," 2012, http://wiki.helsinki.fi/ display/evaluation2011/Survey+on+doctoral+training.

[2] G. Ives and G. Rowley, "Supervisor selection or allocation and continuity of supervision: Ph.D. students' progress and outcomes," Studies in Higher Education, vol. 30, no. 5, pp. 535$555,2005$.

[3] K. Pyhältö, A. Toom, J. Stubb, and K. Lonka, "Challenges of becoming a scholar: a study of experienced problems and wellbeing of doctoral students," ISRN Education. In press.

[4] O. Dysthe, A. Samara, and K. Westrheim, "Multivoiced supervision of Master's students: a case study of alternative supervision practices in higher education," Studies in Higher Education, vol. 31, no. 3, pp. 299-318, 2006.

[5] T. Becher, Academic Ttribes and Territories: Intellectual Enquiry and the Culture of Discipline, Open University Press, Stony Stratford, UK, 1989.

[6] K. S. Kitchener, "Ethical principles and ethical decisions in student affairs," in New Directions for Student Services: Applied Ethics in Student Services, H. J. Canon and R. D. Brown, Eds., pp. 17-29, Jossey-Bass, San Francisco, Calif, USA, 1985.

[7] Academy of Finland, "Ethical Guidelines," 2007, http://www .aka.fi/en-GB/A/Decisions-Impacts/Use-of-funding/.

[8] European Commission, "Ethics for Researchers," Brussels, Belgium, 2007, ftp://ftp.cordis.europa.eu/pub/fp7/docs/ethicsfor-researchers.pdf.

[9] American Psychological Association, "Responsible Conduct of Research,” 2012, http://www.apa.org/research/responsible/ index.aspx.

[10] L. Johnson, A. Lee, and B. Green, "The $\mathrm{PhD}$ and the autonomous self: gender, rationality and postgraduate pedagogy," Studies in Higher Education, vol. 25, no. 2, pp. 135-147, 2000.

[11] J. Stubb, K. Pyhältö, and K. Lonka, "Balancing between inspiration and exhaustion: $\mathrm{PhD}$ students' experienced sociopsychological well-being," Studies in Continuing Education, vol. 33, no. 1, pp. 33-50, 2011.

[12] K. Pyhältö, J. Tuomainen, and J. Stubb, "Exploring the anatomy of fit between doctoral student's and supervisor's perceptions about the resources and challenges in the doctoral journey," Submitted to Studies in Higher Education.

[13] M. Appel and L. Dahlgren, "Swedish doctoral students' experiences on their journey towards a $\mathrm{PhD}$ : obstacles and opportunities inside and outside the academic building," Scandinavian Journal of Educational Research, vol. 47, pp. 89110, 2003.

[14] M. Brauer, J. C. Abric, E. Drozda-Senkowska et al., "Doctoral training in the French-speaking countries of Europe: 
objectives and suggestions for improvement," European Psychologist, vol. 8, no. 1, pp. 9-17, 2003.

[15] International Postgraduate Student Mirror. Catalonia, Finland, Ireland and Sweden, Högskoleverket, Swedish National Agency for Higher Education, 2006.

[16] J. A. Toews, J. M. Lockyer, D. J. G. Dobson, and A. K. Brownell, "Stress among residents, medical students, and graduate science (MSc/PhD) students," Academic Medicine, vol. 68, no. 10, pp. S46-S48, 1993.

[17] S. K. Gardner, "Fitting the mold of graduate school: a qualitative study of socialization in doctoral education," Innovative Higher Education, vol. 33, no. 2, pp. 125-138, 2008.

[18] C. M. Golde, "Should i stay or should i go? Student descriptions of the doctoral attrition process," Review of Higher Education, vol. 23, no. 2, pp. 199-227, 2000.

[19] L. McAlpine and J. Norton, "Reframing our approach to doctoral programs: an integrative framework for action and research," Higher Education Research \& Development, vol. 25, pp. 3-17, 2006.

[20] C. R. Bair and J. G. Haworth, "Doctoral student attrition and persistence: a meta-analysis of research," in Proceedings of the Annual Meeting of the Association for the Study of Higher Education (ASHE '99), San Antonio, Tex, USA, 1999.

[21] B. Kurtz-Costes, L. A. Helmke, and B. Ülküsteiner, "Gender and doctoral studies: the perceptions of Ph.D. students in an American university," Gender and Education, vol. 18, no. 2, pp. 137-155, 2006.

[22] T. Wright, "Postgraduate research students: people in context?" British Journal of Guidance and Counselling, vol. 31, no. 2, pp. 209-227, 2003.

[23] E. R. Welfel, Ethics in Counceling and Psychotherapy: Standards, Research, and Emerging Issues, Brooks/Cole, Pacific Grove, calif, USA, 1998.

[24] S. Vehviläinen and E. Löfström, "The university teacher in the supervision system: an interpretation of challenges and development needs," in Proceedings of the 11th Symposium of the Consortium of Higher Education Researchers in Finland, University of Jyväskylä, August 2011.

[25] L. McAlpine, M. Jazvac-Martek, and N. Hopwood, "Doctoral student experience in education: activities and difficulties influencing identity development," International Journal of Researcher Development, vol. 1, pp. 97-109, 2009.

[26] T. Becher, "The significance of disciplinary differences," Studies in Higher Education, vol. 19, pp. 151-161, 1994.

[27] T. Becher and P. R. Trowler, Academic Tribes and Territories, Open University Press, Buckingham, 2001.

[28] K. Pyhältö, J. Stubb, and K. Lonka, "Developing scholarly communities as learning environments for doctoral students," International Journal for Academic Development, vol. 14, no. 3, pp. 221-232, 2009.

[29] E. Wenger, Communities of Practice. Learning, Meaning, and Identity, Cambridge University Press, Cambridge, UK, 1998.

[30] A. Collins, J. Brown, and S. Newman, "Cognitive apprenticeship: teaching the crafts of reading, writing and mathematics," in Knowing, Learning, and Instruction: Essays in Honor of Robert Glaser, L. B. Resnick, Ed., pp. 453-513, Routledge, 1989.

[31] K. Holley, "Doctoral student socialization in interdisciplinary fields," in On Becoming a Scholar. Socialization and Development in Doctoral Education, S. K. Gardner and P. Mendoza, Eds., pp. 97-112, Stylus Publishing, LLC, Va, USA, 2010.
[32] K. S. Kitchener, "Psychologist as teacher and mentor: affirming ethical values throughout the curriculum," Professional Psychology: Research and Practice, vol. 23, no. 3, pp. 190-195, 1992.

[33] L. E. Schulte, "Graduate education faculty and student perceptions of the ethical climate and its importance in the retention of students," College Student Retention, vol. 3, pp. 119-136, 2001.

[34] M. S. Anderson, K. Seashore Louis, and J. Earle, "Disciplinary and departmental effects on observations of faculty and graduate student misconduct," Journal of Higher Education, vol. 65, pp. 331-350, 1994.

[35] L. E. Schulte, F. Thompson, K. Hayes, J. Noble, and E. Jacobs, "Undergraduate faculty and student perceptions of the ethical climate and its importance in retention," College Student Journal, vol. 34, pp. 565-576, 2001.

[36] P. C. Kelley, B. R. Agle, and J. Demott, "Mapping our progress: identifying, categorizing and comparing universities' ethics infrastructures," Journal of Academic Ethics, vol. 3, no. 2-4, pp. 205-229, 2005.

[37] K. Pyhältö and J. Stubb, "Doctoral students' sense of relational agency in their scholarly communities," Submitted to International Journal of Academic Development.

[38] S. Saari and A. Moilanen, "International Evaluation of Research and Doctoral Training at the University of Helsinki 2005-2010," University of Helsinki, Administrative Publications 81, 2012, http://www.helsinki.fi/julkaisut/ aineisto/hallinnon_julkaisuja_81_2012.pdf.

[39] J. Sainio, "Entering the job market as an expert—employment and views about doctoral training among graduates from doctoral programmes in 2006 and 2007," Career and recruitment services of Finnish universities \& Ministry of Education, 2010, http://www.aarresaari.net/pdf/Asiantuntijana_tyomarkkinoille_netti.pdf.

[40] R. P. Weber, Basic Content Analysis, Sage, Newbury Park, Calif, USA, 1985.

[41] C. Marshall and G. B. Rossman, Designing Qualitative Research, Sage, London, UK, 1995.

[42] G. S. Åkerlind, "Academic growth and development—how do university academics experience it?" Higher Education, vol. 50, no. 1, pp. 1-32, 2005.

[43] R. K. Goodyear, C. A. Crego, and M. W. Johnston, "Ethical issues in the supervision of student research: a study of critical incidents," Professional Psychology: Research and Practice, vol. 23, no. 3, pp. 203-210, 1992.

[44] J. Walker, "Measuring plagiarism: researching what students do, not what they say they do," Studies in Higher Education, vol. 35, no. 1, pp. 41-59, 2010.

[45] B. G. Tabachnick, P. Keith-Spiegel, and K. S. Pope, "Ethics of teaching: beliefs and behaviors of psychologists as educators," American Psychologist, vol. 46, no. 5, pp. 506-515, 1991.

[46] S. K. Gardner, "II heard it through the grapevine": doctoral student socialization in chemistry and history," Higher Education, vol. 54, no. 5, pp. 723-740, 2007. 


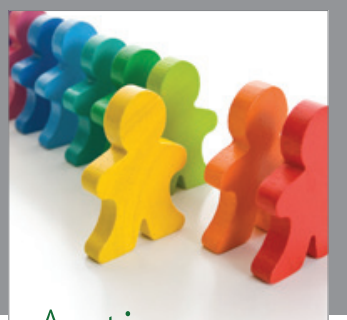

Autism

Research and Treatment
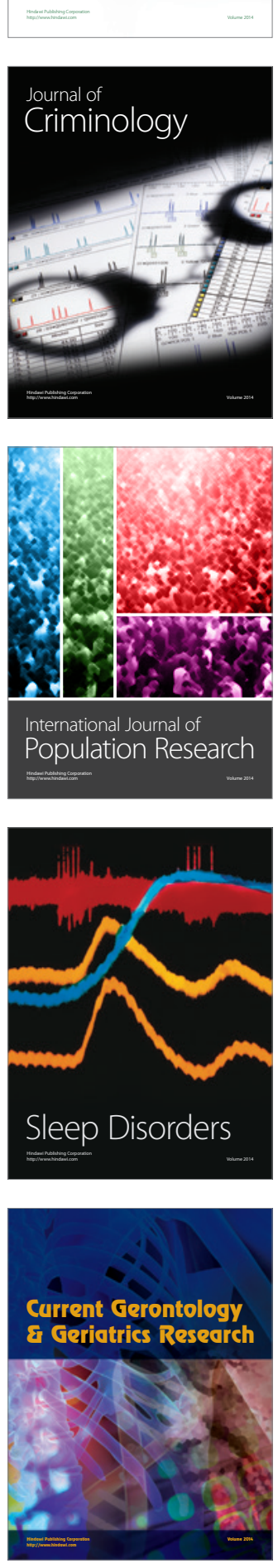
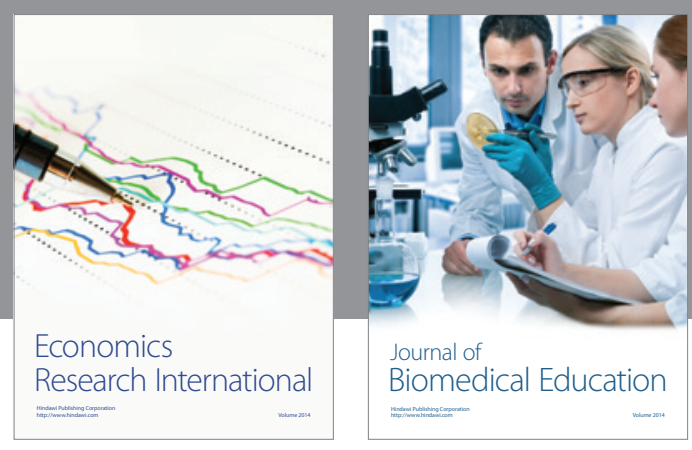

Journal of

Biomedical Education

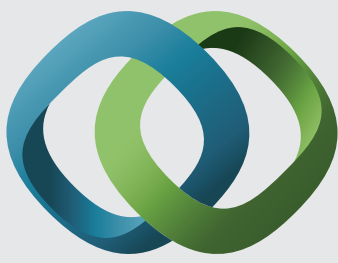

\section{Hindawi}

Submit your manuscripts at

http://www.hindawi.com
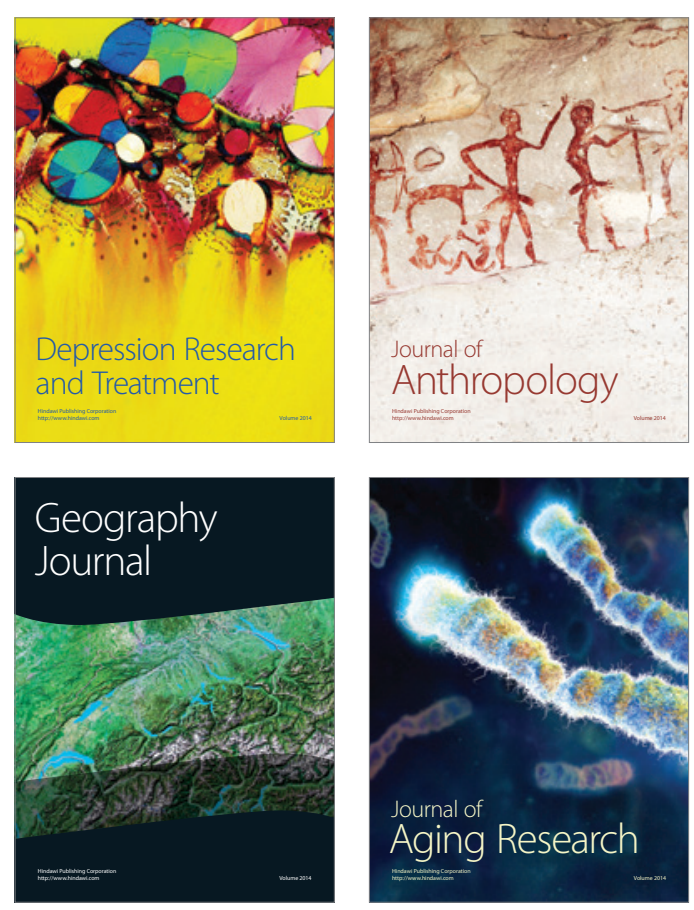

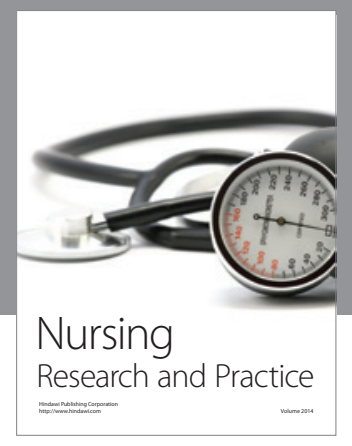

Nursing

Research and Practice

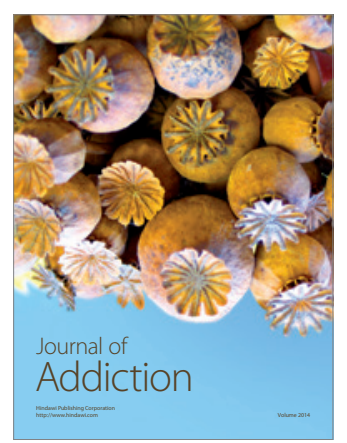

Child Development

Research

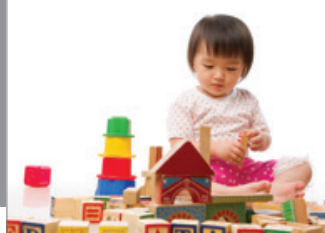

迥
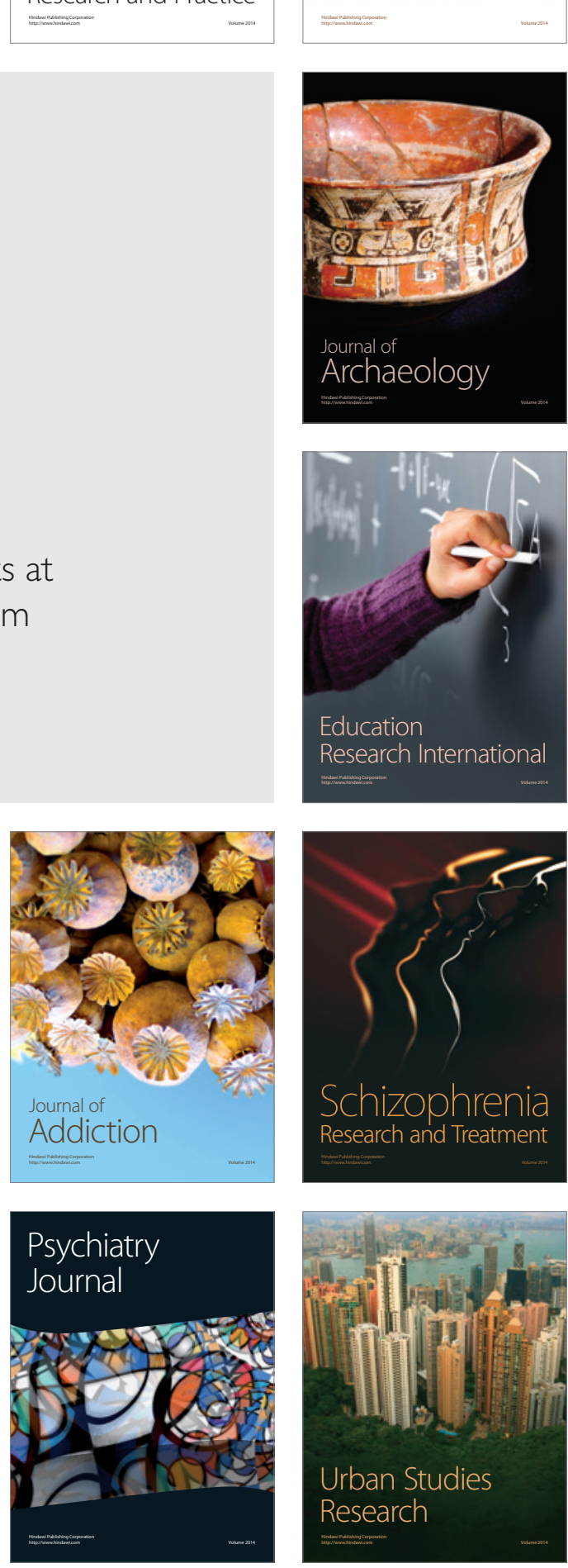